\section{Dream recall and content following various durations of sleep}

JOHN M. TAUB, ${ }^{\prime}$ Merrill College, University of California, Santa Cruz, Calif. 95060

An exploratory study was conducted to investigate the influence of various durations of sleep on dream recall and content. Ten Ss reported dreams on 5 mornings, separated by $S$-day intervals, following $5,6 \frac{1}{2}, 8,9 \%$, and $11 \mathrm{~h}$ of nocturnal sleep. The total number of dreams reported subsequent to extended sleep $(91 / 2$ and $11 \mathrm{~h})$ was significantly higher than the number reported after sleep deprivation $\left(5\right.$ and $\left.6 \frac{1}{2} h\right)$ and $8 h$ of sleep $(p<.01)$. Recall did not vary significantly between the 8-h condition and both conditions of sleep deprivation. There were no significant differences in dream content following the various durations of sleep. The results indicate that extended sleep is more favorable for dream recall than are shorter sleep periods.

The relation of dream content and recall to varying amounts of sleep has not previously. been studied. However, the relation of dream recall to the probability of rapideye-movement (REM) periods in the last hours of an 8-h night of sleep has been investigated (Webb \& Kersey, 1967). While recent research has demonstrated the deleterious consequences of both sleep deprivation and extended sleep on performance (Wilkinson, Edwards, \& Haines, 1966; Taub \& Berger, 1969), findings have not been related to mental activity accompanying such sleep durations. It ought not to be presupposed that sleep is a unitary phenomenon integrally influencing both the behavioral factor of performance and the psychological variable of dreams. An interesting possibility is that the type and quantity of dreams are contributing determinants to the qualitative effects of sleep. The scope of this present experiment was exploratory, and its purpose was to study the influence of varying quantities of sleep on dream content and recall.

\section{SUBJECTS}

The Ss were 10 normal male students of college age, composing five pairs of dormitory roommates.

\section{PROCEDURE}

The Ss were requested to abstain from all stimulating or soporific drugs, including amphetamines, barbiturates, heavy doses of alcohol, and psychedelics, for 3 days preceding their first night under experimental conditions and until after the last. This period spanned a duration of 28 days. The Ss were directed not to drink alcohol, coffee, or tea after 6 p.m. on evenings of sleep in the experimental situation. On the same day they were requested to abstain from naps. The setting of the experiment was a dormitory room.

For each set of Ss, the experiment comprised 5 nights of sleep that were separated by a 5-day interval to allow recovery from each sleep condition. Ss were always awakened at 9:00 a.m. The sleep-deprivation conditions consisted of 5 and $6 \frac{1}{2} \mathrm{~h}$ of sleep, with Ss retiring at 4:00 a.m. and 2:30 a.m., respectively. For the 8 -h condition, they retired at 1:00 a.m. The conditions of extended sleep comprised nights when Ss slept $9 \frac{1}{2}$ and 11 h by retiring at 11:30 and 10:00 p.m., respectively.

The dreams were independently scored, using the methods of content analysis developed by Hall \& Van de Castle (1966). The measure for dream recall was the total number of dreams reported by all Ss following each condition of sleep.

\section{RESULTS}

Table 1 shows the number of dreams reported subsequent to each duration of sleep for each $S$. The statistical comparison between the sleep-deprivation ( 5 and $61 / 2 h$ ) and extended-sleep (91/2 and $11 \mathrm{~h})$ conditions was based upon the total number of dreams reported per $\mathbf{S}$ following both nights under each condition. The total number of dreams reported on mornings following extended sleep was significantly higher than that after sleep deprivation (Table 1; $\mathrm{p}<.01$, two-tailed Wilcoxon test). Also, there were significantly more dreams recalled on mornings after the $91 / 2-h$ and $11-h$ conditions than following the 8-h duration of sleep (Table 1; p<.01, two-tailed Wilcoxon test). Recall did not differ significantly between the 8 -h condition and

Table 1

Total Number of Dreams Recalled After Five Durations of Sleep

\begin{tabular}{|c|c|c|c|c|c|}
\hline \multirow[b]{3}{*}{ Ss } & \multicolumn{5}{|c|}{ Condition } \\
\hline & \multicolumn{2}{|c|}{$\begin{array}{c}\text { Sleep } \\
\text { Deprivation }\end{array}$} & \multirow[b]{2}{*}{$8 \mathrm{~h}$} & \multicolumn{2}{|c|}{$\begin{array}{c}\text { Extended } \\
\text { Sleep }\end{array}$} \\
\hline & $5 \mathrm{~h}$ & $6^{1 / 2 h}$ & & $91 / 2 \mathrm{~h}$ & $11 \mathrm{~h}$ \\
\hline D.K. & & & & 2 & \\
\hline R.S. & 1 & & 1 & 1 & 1 \\
\hline D.J. & & 1 & & & 1 \\
\hline $\begin{array}{l}\text { L. K. } \\
\text { N. }\end{array}$ & & $\begin{array}{l}1 \\
1\end{array}$ & & $\begin{array}{l}1 \\
1\end{array}$ & $\begin{array}{l}3 \\
1\end{array}$ \\
\hline S.K. & 1 & 1 & 1 & 1 & 1 \\
\hline B.L. & & 1 & 1 & 1 & 1 \\
\hline R.H. & 1 & 1 & & 1 & 2 \\
\hline $\begin{array}{l}\text { E.F. } \\
\text { C.H. }\end{array}$ & 1 & 1 & 1 & $\begin{array}{l}2 \\
1\end{array}$ & 1 \\
\hline Totals & 4 & 7 & 4 & 11 & 11 \\
\hline
\end{tabular}

both sleep-deprivation conditions (Table 1; $\mathrm{p}>.05$, two-tailed Wilcoxon test).

Differences in dream content for each $S$ between the five sleep durations were not significant.

\section{DISCUSSION}

Webb \& Kersey (1967) found that the frequency of dream recall on awakening during the last hour of an 8-h night of sleep was related to the probability of having been awakened from a REM period. Other studies show that the amount of REM sleep increases with time throughout a typical night of 7 or $8 \mathrm{~h}$ of sleep (Dement \& Kleitman, 1957; Feinberg, Koresko, \& Heller, 1967; Kales, Jacobson, Kales, Kun, \& Weissbuch, 1967). But, these findings do not provide an explanation for the absence of significant differences in dream recall between the conditions of sleep deprivation and $8 \mathrm{~h}$ of sleep. It also seems unlikely that the larger number of dreams recalled following extended sleep was due to the increasing probability of being awakened from REM periods, since Verdone (1968) found that the proportion of REM sleep does not continue to increase bexond $8 \mathrm{~h}$ of sleep.

That the frequency of dream recall following extended sleep was higher than it was after shorter durations might be explained by the fact that there was a longer period of time for dreaming to occur, or that lighter sleep stages and occasional awakenings predominate toward the termination of sleep and allow Ss more time to think about their dreams.

\section{REFERENCES}

DEMENT, W., \& KLEITMAN, N. Cyclic variations in EEG during sleep and their relation to eye movements, body motility and dreaming. Electroencephalography \& Clinical Neurophy siology, 1957, 9, 673-690.

FEINBERG, I., KORESKO, R., \& HELLER, N. EEG sleep patterns as a function of normal and pathological aging in man. Journal of Psychiatric Research, 1967, 5, 107-144.

HALL, C. S., \& VAN de CASTLF, R. L. The content analysis of dreams. New York: Appleton-Century-Crofts, 1966.

KALES, A., JACOBSON, A., KALES, J., KUN, T., \& WEISSBUCH, R. All-night EEG sleep measurements in young adults. Psychonomic Science, 1967, 7, 67-68.

TAUB, J., \& BERGER, R. Extended sleep and performance: The Rip Van Winkle effect. Psychonomic Science, 1969, 16, 204-205.

VERDONE, P. Extended sleep in normal subjects, Electroencephalography \& Clinical Neurophysiology, 1968, 24, 417-423.

WEBB, W., \& KERSEY, J. Recall of dreams and the probability of stage I REM sleep. Perceptual \& Motor Skills, 1967, 24, 627-630. WILKINSON, R., EDWARDS, R., \& HAINES, E. Performance following a night of reduced sleep. Psychonomic Science, 1966, 5, 471-472. NOTE

1. Address requests for reprints to John $M$. Taub, Merrill College, University of California, Santa Cruz, California 95060. My grateful acknowledgment and thanks to Dr. Calvin Hall for performing the content analyse's and to both him and Dr. Ralph Berger for their advice and encouragement. 